\title{
Reconstruction of the Hip after Septic Arthritis and Complete Absence of Femoral Head and Neck in Children
}

\author{
Ali Zein A.A. Alkhooly ${ }^{1 *}$ and Ahmed ali \\ Z.A.A.Alkhooly ${ }^{2}$ \\ ${ }^{1}$ Department of Ortho and Trauma, Minia University \\ Hospital, Egypt \\ ${ }^{2}$ Department of Ortho and Trauma, Matai General \\ Hospital (El-Minia), Egypt \\ *Corresponding author: Ali Zein Alabdeen Ahmed \\ Alkhooly, Department of Ortho and Trauma, Minia \\ University Hospital, Egypt
}

Received: J anuary 16, 2017; Accepted: February 22, 2017; Published: February 24, 2017

\begin{abstract}
Septic arthritis of hip joint in children may lead to many complications; the study represents a female patient aged seven years with complete absence of femoral head and neck after previous history of septic arthritis the protocol of management as the following manner: debridement with traction, deepening acetabular osteotomy and subtrochanteric osteotomy combined with trochanteric epiphysis transposition into deepened acetabulum. The result was good in relation to hip movement after period of follow-up, the only residual problem was limb shorting which managed later on.
\end{abstract}

Keywords: Arthritis; Hip joint; Hip replacement

\section{Introduction}

Septic arthritis of the hip joint is an orthopedic emergency. Combined osteoarticular affection should be kept in mind in cases which show a poor response after initial treatment. Early surgical decompression is the treatment of choice. Septic arthritis may lead to dislocation, subluxation, dysplasia, coxa vara, absence of head and neck of femur and post septic arthritis. Numerous reconstructions procedure such as open reduction, pelviclfemoral osteotomy and greater trochanterplasty has been advocated to treat the residual deformity. My study represents a case with complete absence of femoral head and neck after previous history of septic arthritis and this case managed by staged reconstruction procedures of hip joint in the following manner: debridement with traction, deepening acetabular osteotomy and subtrochanteric osteotomy combined with trochanteric epiphysis transposition into deepened acetabulum.

\section{Material and Methods}

Seven years female patient presented in our hospital by limping of left lower limb with past history of infection in the left hip joint 5 years age (age of patient $=2$ years), also past history of operation 3 years ago. Examination revealed supra-trochanteric shortening of left lower limb about $8 \mathrm{~cm}$ with limitation of movement of hip joint. X ray revealed complete absence of head and neck of femur with upward migration of greater trochanter toward iliac bone (Figure 1).

The first procedure was debridement and removal of all necrotic and fibrotic tissue inside the hip and capsular remnant and realse origin of abductors of hip joint followed by traction for 1 month to diminish muscle spasm, upward migration of the proximal femur and facilitate the next step of refashioning of the proximal femur to allow recontaiment of the proximal femur inside the deepened acetabulum (Figure 2).

The second operation was performed for deepening of acetabulum using Chiari osteotomy to increase acetabular surface area and help in more containment of fashioned proximal femur (Figure 3).

After complete solid healing of osteotomy site at iliac bone, the third operation was applied in the form of; subtrochanteric osteotomy at proximal femur to make newly formed neck shaft angle and angulate the proximal fragment of osteotomy to be contained inside the deepened acetabulum [ transposition of trochantric epiphysis ] and supported by using transarticular $\mathrm{K}$ wire fixation in reformed acetabulum. The osteotomy site was fixed by contoured angled plate about $120^{\circ}$ (Figure 4). After that transposition of abductor insertion was done as an essential step to be sutured in the proximal femur to preserve the abductor mechanism. (Figure 5) closure of the skin; and hip spica was applied.

\section{Postoperative regimen}

Skin Suture was removed after two weeks; Transarticular K wire and hip spica were removed after 6 weeks and serial follow up $\mathrm{x}$ rays

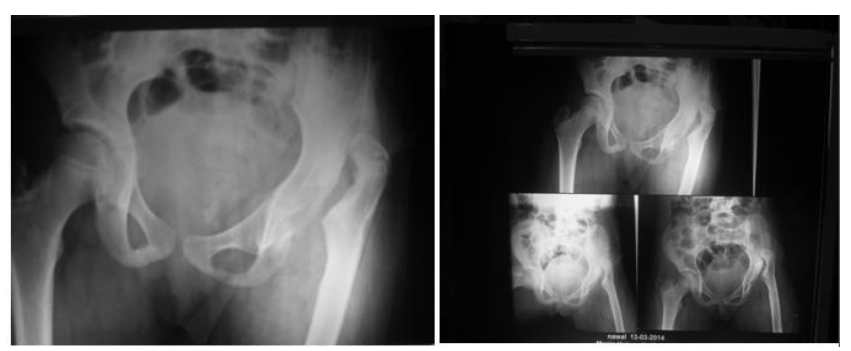

Figure 1: $X$ ray revealed complete absence of head and neck of femur with upward migration of greater trochanter toward iliac bone.

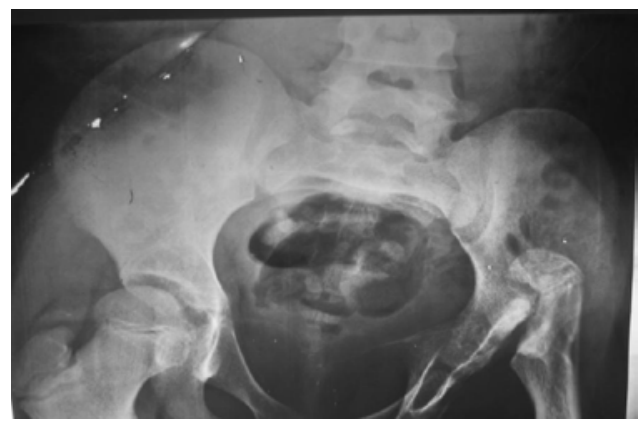

Figure 2: Depridment and refashioning of the proximal femur to allow recontaiment of the proximal femur inside the deepened acetabulum.
Austin J Orthopade \& Rheumatol - Volume 4 Issue 1 - 2017 ISSN: 2472-369X | www.austinpublishinggroup.com

Alkhooly et al. (C) All rights are reserved
Citation: Ali Zein A.A. Alkhooly and Ahmed Ali Z.A.A. Alkhooly. Reconstruction of the Hip after Septic Arthritis and Complete Absence of Femoral Head and Neck in Children. Austin J Orthopade \& Rheumatol. 2017; 4(1): 1048. 


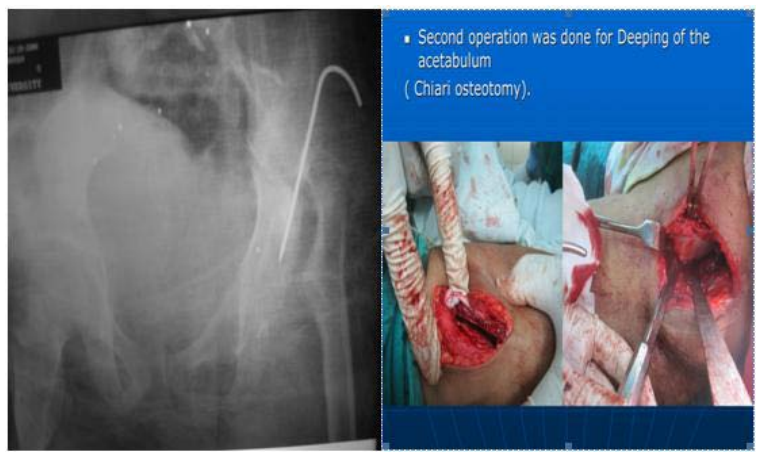

Figure 3: X-ray and photo show Chiari osteotomy to increase acetabular surface area and help in more containment of fashioned proximal femur.

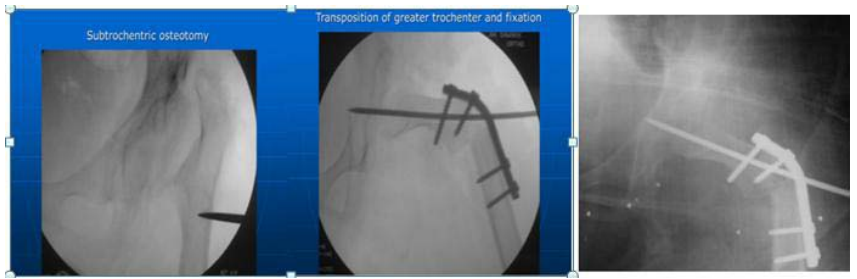

Figure 4: Subtrochanteric osteotomy at proximal femur and angulate the proximal fragment of osteotomy to be contained inside the deepened acetabulum [transposition of trochantric epiphysis] and supported by using transarticular $\mathrm{K}$ wire fixation in reformed acetabulum. The osteotomy site was fixed by contoured angled plate about $120^{\circ}$.

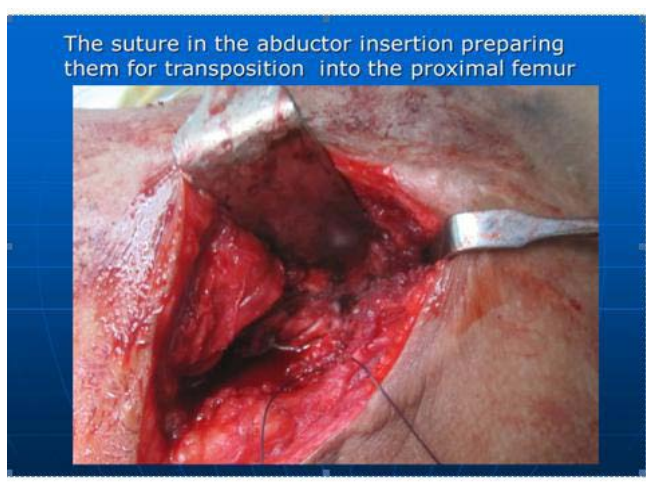

Figure 5: Suture in abductore insertion.

were conducted until more than one year (Figure 6).

\section{Results}

Newly formed spherical head appear in this girl with good acetabular containment without any arthrosis with slight reduction of cartilage height. The patient restores almost all movement of the hip (flexion, extension, rotation, adduction and abduction) with painless hip joint allowing good walking function with good range of movement after one year (Figure 7). The only problem in this case after procedures was leg length discrepancy about $8 \mathrm{~cm}$ to be corrected using iliazrov technique and removal of plate.

\section{Discussion and Conclusion}

Complete loss of femoral head and neck is a disastrous complication after septic arthritis in children in early life.

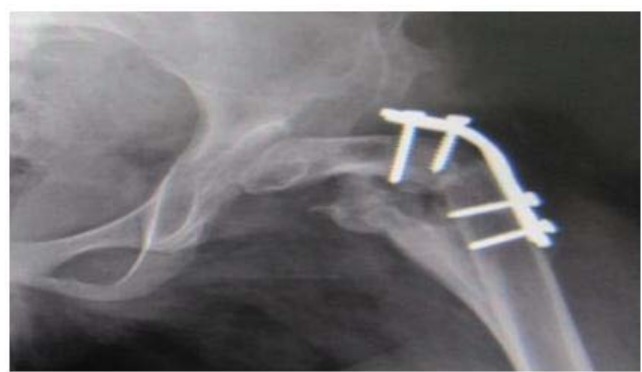

Figure 6: X-ray after removal of k. wire.

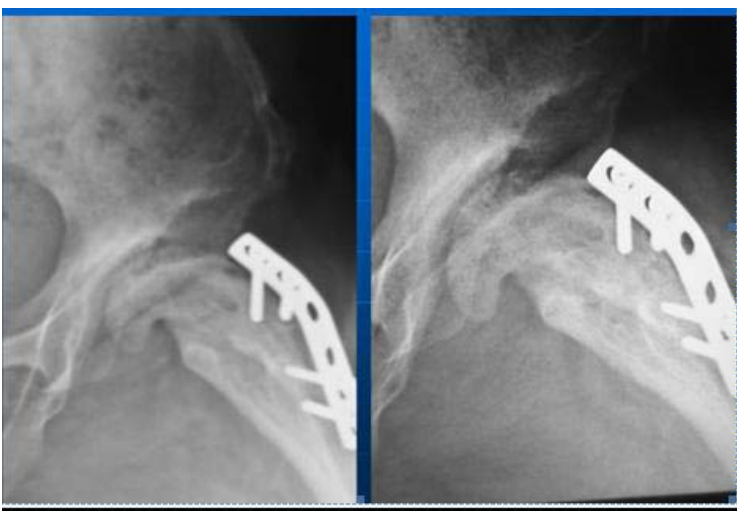

Figure 7: X-ray show hip joint after one year follow up.

Femoral head and neck necrosis and loss after sepsis described by Thomas Smith [1] and he described that head and neck after death had been completely destroyed in some case

Proximal migration of proximal femur and complete loss of head and neck after neglected or mallundertreated septic arthritis of the hip in children is problematic harmful complication

Limited procedures have been done to treat this squeal

Various forms of reconstructive procedures have been described that attempt to salvage the hip joint with the goal of making a stable painless articulation L'Episcopo JB procedure [2], colonna [3], Hallel and Salvati [4], freeland et al. [5].

L'Episcope , [2] attempted to stabilize the hip in child with complete loss of femoral head by splitting the proximal end of the remaining femur and bent the medial portion into acetrbulum.

Primary subtrochanteric osteotomy combined with transposition of the trochanteric apophasis was first described by Weissman SL [6] In his case, the procedure resulted in an ankylosed hip

Furthermore, Stetson et al. [7] reported one case operated with the same procedure. There was practically no motion in this hip 11 years after operation also Stetson et al. [7], Dobbs et al. [8] with limited cases and follow up.

Some studies have shown some satisfactory results up to 12 years after subtrochanteric osteotomy and transposition of the apophasis of the greater trochanter into the acetabulum in children with total femoral head necrosis due to septic arthritis; Benum P [9].

Hunka et al. [10] reported satisfactory results in 3 of 5 children 

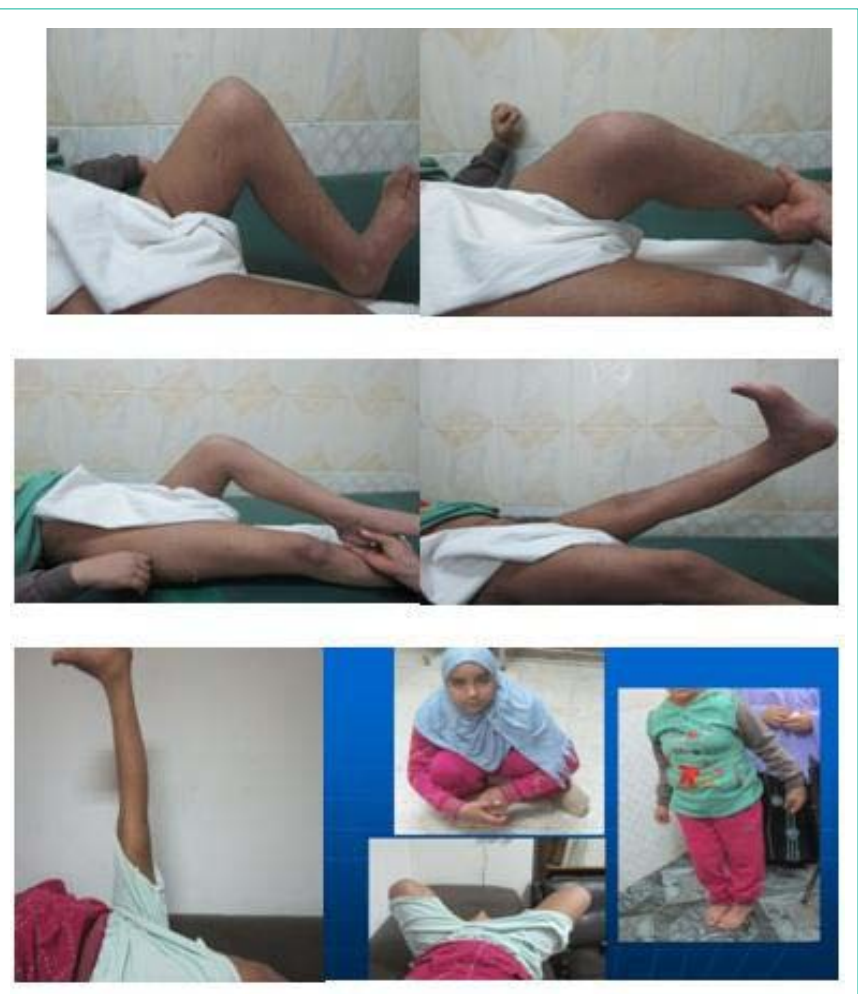

Figure 8: The clinical result after one and half year as shown.

8-12 years after trochanteric arthroplasty with primary osteotomy.

Transposition of greater trochanter apophasis is an interesting biological point allowing to be developed from traction apophasis to compression epiphysis like structure and changing it from being traction to be pressure and friction. This transposition adapts to the opposite joint surface to be nearly spherical shaped head by remodeling. In this case, slight reduction of cartilage height was observed due to unossified superficial layer of new articular surface.

The osseous nucleus grows and is remodeled into a spherical joint-end which adapts to the opposite joint surface. Under normal conditions, all the cartilage of an apophasis' is completely ossified at the end of the growth period. After transposition to the joint, this process seems to be modified leaving the most superficial layers of the new articulating surface unossified, like what was seen when apophyseal cartilage was transplanted to joint defects by Benum $\mathrm{P}$ [11].

In our case three procedures were performed to decrease proximal migration of femur, relocate fashioned proximal femur into the newly deepened acetabulum and maintain the containment of newly formed proximal femur into the acetabulum to allow reshaping of the greater trochanter apophasis' to become a spherical shaped head and restore nearly normal function of the hip joint. Chiari osteotomy is one of simplest acetabular osteotomy performed to increase acetabular surface area and coverage of trochanteric apophysis into the reformed acetabulum. Stable sub- trochanteric of proximal femur using angled contoured plate allowed reformation of new neck shaft angle helping in more concentric reduction and containment of trochanteric apophasis after transposition.

In our case the procedures were summarized as follows:

- Debridement and traction.

- Deeping of acetabulum.

- Subtrochanteric o apophasis steotomy combined with transposition of trochanteric apophasis into reformed acetabulum.

- The result was good in short period of follow up.

The conclusion from this case that deepening acetabular, sub trochanteric osteotomy with greater trochanter apophysis transposition in cases with complete femoral head and neck loss after septic necrosis is beneficial and result in a favorable outcomes also preparation of proximal femur for any other procedure [hip replacement] however the next important operation in this case is correction of leg length discrepancy whice done later on, the clinical result after one and half year as shown in the following photo (Figure $8)$.

\section{References}

1. Smith T. On the acute arthritis of infants. St. St. Bartholomew's Hospital Reports. 1874; 10: 189.

2. L'Episcopo JB. Stabilization of pathological dislocation of the hip in children. J Bone Joint Surg Am. 1936; 18: 737-742.

3. Colonna PC. A new type of reconstruction operation for old ununited fracture of the neck of the femur. J Bone Joint Surg. 1935; 17: 110-122.

4. Hallel T, Salvati EA. Septic arthritis of hip in infancy. End result study. Clin Orthop Relat Res. 1978; 132: 115-128.

5. Freeland AE, Sullivan DJ, Westin GW. Greater trochanteric hip arthroplasty in children with loss of the femoral head. J Bone Joint Surg Am. 1980; 62: 1351-1361.

6. Weissman SL. Transplantation of the trochanteric epiphysis into the acetabulum after septic arthritis of the hip. Report of a case. J Bone Joint Surg Am. 1967; 49: 1647-1651.

7. Stetson JW, DePonte RJ, Southwick WO. Acute septic arthritis of the hip in children. Clin Orthop. 1968; 56: 105-116.

8. Dobbs MB, Sheridan JJ, Gordon JE, Corley, Carey L BSN, Szymanski, et al. Septic arthritis of the hip in infancy: long-term follow-up. J Pediatr Orthop. 2003; 23: 162-168.

9. Benum P. Transposition of the apophysis of the greater trochanter for reconstruction of the.femoral head after septic hip arthritis in children. Acta Orthop. 2011; 82: 64-68.

10. Hunka L, Said SE, MacKenzie DA, Rogal AEJ, Cruess RL. Classification and surgical management of the severe sequela of septic hips in children. Clin Orthop. 1982; 171: 30-36.

11. Benum P. Tansposition of apophyseal cartilage to osteochondral defects of joints. An experimental study in dogs. Acta Orthop Scand. 1974.
Austin J Orthopade \& Rheumatol - Volume 4 Issue 1 - 2017 ISSN: 2472-369X | www.austinpublishinggroup.com Alkhooly et al. (C) All rights are reserved
Citation: Ali Zein A.A. Alkhooly and Ahmed Ali Z.A.A. Alkhooly. Reconstruction of the Hip after Septic Arthritis and Complete Absence of Femoral Head and Neck in Children. Austin J Orthopade \& Rheumatol. 2017; 4(1): 1048. 